\title{
RESEARCH
}

Open Access

\section{A randomized controlled study of immediate versus delayed umbilical cord clamping in infants born by elective caesarean section}

Giuseppe De Bernardo ${ }^{1 *}$ D, Maurizio Giordano ${ }^{2}$, Rita De Santis ${ }^{3}$, Paola Castelli', Desiree Sordino ${ }^{5}$, Daniele Trevisanuto ${ }^{6}$, Giuseppe Buonocore ${ }^{7}$ and Serafina Perrone ${ }^{8}$

\begin{abstract}
Background: Delayed umbilical cord clamping is associated with greater haemoglobin concentration and iron storage between 3 and 6 months of life and with less need of blood transfusion and lower incidence of neonatal hypotension compared to early umbilical cord clamping.

Methods: The aim was to test the hypothesis that delayed cord clamping is better than early cord clamping in term infants born by elective caesarean section. Group A was subjected to immediate cord clamping while in the Group B, the umbilical cord was clamped 1 min after birth. Primary aim was revealed the difference in pre-ductal saturation between two groups while secondary aim was investigating the difference in $\mathrm{HR}$, $\mathrm{Ht}$, bilirubin and glycaemia. Pre-ductal $\mathrm{SpO}_{2}$ and $\mathrm{HR}$ were recorded at 5 and 10 min after birth, T was analysed 10 min after birth, glycaemia was revealed at 120 min while $\mathrm{Ht}$ and bilirubin were collected at $72 \mathrm{~h}$.

Results: 132 newborns were enrolled in the study and allocated in ratio 1:1 to group A or B. Delayed cord clamping did not improve $\mathrm{SpO}_{2}, \mathrm{HR}$ and T values compared to immediate cord clamping $(p>0,05)$. However, Group B showed greater haematocrit and bilirubin values at $72 \mathrm{~h}$ compared to Group A $(56,71 \pm 6663$ vs $51,56 \pm 6929 ; p<0,05$ and 8 , $54 \pm 2,90$ vs $7,06 \pm 2,76 ; p<0,05)$. Glycaemia value did not differ between two groups $(p>0,05)$.
\end{abstract}

Conclusions: Group B did not reveal any differences in $\mathrm{SpO}_{2}, \mathrm{HR}$, T and glycaemia compared to Group A. Group B showed greater values of haematocrit and bilirubin but without need of phototherapy.

Trial registration: Umbilical Cord Clamping: What Are the Benefits; NCT03878602. Registered 18 March 2019 retrospectively registered.

Keywords: Newborns, Delayed cord clamping, Elective caesarean section

\footnotetext{
* Correspondence: pinodebtin@gmail.com

'Division of Pediatrics Neonatology and NICU, Ospedale Buon Consiglio

Fatebenefratelli, Via Manzoni 220, 80123 Naples, Italy

Full list of author information is available at the end of the article
}

(c) The Author(s). 2020 Open Access This article is licensed under a Creative Commons Attribution 4.0 International License, which permits use, sharing, adaptation, distribution and reproduction in any medium or format, as long as you give appropriate credit to the original author(s) and the source, provide a link to the Creative Commons licence, and indicate if changes were made. The images or other third party material in this article are included in the article's Creative Commons licence, unless indicated otherwise in a credit line to the material. If material is not included in the article's Creative Commons licence and your intended use is not permitted by statutory regulation or exceeds the permitted use, you will need to obtain permission directly from the copyright holder. To view a copy of this licence, visit http://creativecommons.org/licenses/by/4.0/ The Creative Commons Public Domain Dedication waiver (http://creativecommons.org/publicdomain/zero/1.0/) applies to the data made available in this article, unless otherwise stated in a credit line to the data. 


\section{Background}

Umbilical cord cutting determines the separation of the newborn from mother. Umbilical cord clumping consists in its binding by nipper to interrupt blood flow from placenta to foetus [1]. Experimental studies, executed on animals and humans, analysed cardiocirculatory changes in the foetus immediately after birth and the importance of the delayed cord clamping (DCC) for the hemodynamic stabilization, particularly in the lowest gestational age $[2,3]$. In the eutocic delivery there are two modalities to obtain umbilical cord clamping: the first is immediate umbilical cord clamping (ICC) within 30s from birth, the second one is delayed DCC at least $1 \mathrm{~min}$ after birth because cerebral blood flow is reduced again due to lower cardiac output $[4,5]$. DCC is better than ICC because it is associated with a great haemoglobin concentration in the newborns and best iron storage between 3 and 6 months of life and less incidence of transfusion and neonatal hypotension [6-9]. In a recent randomized study conducted in Nepal on 540 newborns, birth by eutocic delivery at term of gestational age, showed that DCC after $3 \mathrm{~min}$ of life is correlated with a better haemoglobin level and less incidence of anaemia at 8 months of life [10]. Association of Italian Hospital Gynaecologists Obstetricians declared contraindicated conditions to execute a DCC: Hypoxic-ischemic events: detachment of placenta, prolapse of the funiculus, uterine rupture, shoulder dystocia, premature rupture of foetal membranes, placenta previa, maternal collapse, embolism amniotic, maternal cardiac arrest, monochorionic twins, foetal hydrops, umbilical cord damaged, isoimmunization Rh. Zhou et al. conducted a meta-analysis to evaluate the differences between caesarean section (CS) and vaginal delivery (VD) with regard to hematologic parameters obtained by umbilical cord, placenta and newborns' blood. It was revealed that CS was associated with an increased placental residual blood volume and a decreased level of iron-related haematological indices including haematocrit, haemoglobin, and erythrocyte in both cord and peripheral blood in term neonates at 3 or $6 \mathrm{~h}$ of life. This difference on placental transfusion could be caused to a weaker transfusion force and a shorter transfusion period during CS due to ICC. Weighted mean difference of haematocrit value was significantly greater in infants born by elective caesarean section (ECS) than those born by emergency CS [11]. However, authors did not analyse the effects of the timing of cord clamping on hematologic parameters in relation to the different mode of delivery. Therefore, despite the evidence of beneficial effects for umbilical cord delay after eutocic delivery, this practice has not yet been evaluated after ECS.

\section{Material and methods}

\section{Aims}

Primary aim of the study was evaluating the effect of DCC compared to ICC on pre-ductal $\mathrm{SpO}_{2}$ in infants born by ECS. Secondary aims were analysing the differences of heart rate (HR), temperature (T), glycaemia, haematocrit $(\mathrm{Ht})$ and bilirubin.

\section{Participants}

Non-commercial study, case-control, randomized, open was conducted to Department of mother and child's health, Poliambulanza Foundation, Brescia. The study was recorded and publicly accessible at https://clinicaltrials. gov/ct2/show/NCT03878602?term=de+bernardo\&rank=3. Term infants born by ECS were enrolled between March and August 2018 and assigned to Group A if were subjected to ICC and to Group B if were subjected to DCC. The study was approved by Brescia Ethical Committee and written informed consent was obtained from the families. Eligibility criteria for mothers were BMI > 19 and < 25 and age $\leq 37$ years. They were excluded mothers with pathologies, toxicomaniac and those who smoked or assumed drugs during pregnancy. Eligibility criteria for newborns were, gestational age $=37-42$ wks, birth body weight appropriate for gestational age. Newborns admitted in NICU, and who needed neonatal resuscitation were excluded. They were excluded also newborns that showed hypoxic-ischemic events: detachment of placenta, prolapse of the funiculus, uterine rupture, shoulder dystocia, premature rupture of foetal membranes, placenta previa, maternal collapse, embolism amniotic, maternal cardiac arrest. Finally, they were excluded monochorionic twins, foetal hydrops, umbilical cord damaged, isoimmunization $\mathrm{Rh}$, respiratory and malformative diseases.

\section{Procedure and randomization}

Umbilical cord management was established before birth. All eligible infants were assigned to group A or B by block randomization thanks a statistical software. In operating room, a nurse turned on a timer after birth and gynaecologist clamped umbilical cord immediately after birth or at $1 \mathrm{~min}$. DCC was chosen at $1 \mathrm{~min}$ to avoid maternal bleeding, infections or other surgeryrelated complications [11]. It was promoted neonatal bonding to improve mother-child relationship and then the baby was covered with sterile towels. After neonatal bonding, the infant was positioned under the infant warmer, dried and stimulated. A pulse-oximeter (Covidien) was utilized to evaluate newborn saturation level and positioning the probe on the right hand or wrist, reference values were $80-85 \%$ and $85-95 \%$, respectively at $5 \mathrm{~min}$ and $10 \mathrm{~min}$ after birth [12]. HR was evaluated by a Cardiomonitor (Transport Pro, GE Healthcare) and positioning the probes on the chest of the newborn, reference values were $100-150 \mathrm{bpm}$ [12]. T was analysed by the probe of the infant warmer (Panda Warmer, GE Health Care). Pre-ductal saturation and HR were recorded at 5 and 10 min after birth while $\mathrm{T}$ was analysed 
at 10 min after birth along with Apgar Score to evaluate perinatal adaptation of the newborns. Capillary blood samples of the heel were analysed by ABL90 Flex to evaluate glycaemia (at 120 min from birth), Ht and bilirubin (at $72 \mathrm{~h}$ from birth). These variables were collected in according to protocol procedures to monitor neonatal health status. During hospital stay was promoted rooming-in $24 \mathrm{~h}$. Data were recorded using a database (Excel 2007) by a nurse that was aware of the study aims. Parameters collected were sex, gestational age, birth body weight, Apgar score at 5 and $10 \mathrm{~min}$, HR, pre-ductal $\mathrm{SpO}_{2}$, T, glycaemia, $\mathrm{Ht}$, bilirubin.

\section{Statistical analysis}

Statistical analysis was carried out by a statistician who was aware of the study aim using SPSS version 25.0 for Windows (IBM, Armonk, NY, USA). Normal distribution of data was evaluated by Kolmogorov-Smirnov test. Parametric data were analysed by ANOVA repeated measures between-whitin or ANOVA, as appropriate. Non-parametric data were analysed by $x^{2}$ test. Sample size required to execute this study was 132 . This analysis was computed by G*Power 3.9.1.2 for windows [13] setting: $\alpha=5 \%, \beta=10 \%$, number of measurements $=2$, correlation of repeated measures $=0.5$, non-sphericity correlation $=1$, effect size $=0,14$. In 1969 Cohen has defined the following conventional effect sizes if data was not available to calculate it without overestimating the power: small $\mathrm{f}=0.14$; medium $\mathrm{f}=0.25$; large $\mathrm{f}=0.40$ [14]. All data with $p<0,05$ were considered statistically significant.

\section{Results}

A total of 150 pregnant women were approached for recruitment. However, in the final analysis were included 132 term newborns and allocated in ratio 1:1 in group A or B (Fig. 1). There were not statistically significant differences between groups for $\mathrm{SpO}_{2}, \mathrm{HR}$ and $\mathrm{T}$ both at 5 min and at $10 \mathrm{~min}$ from birth (Table 1). No difference was also found in glycaemia at $120 \mathrm{~min}$, but greater values $\mathrm{Ht}$ and bilirubin were observed in group B compared to group A at $72 \mathrm{~h}$ of life (Table 1).

\section{Discussion}

Our findings indicated that delaying cord clamping after $60 \mathrm{~s}$ increased haematocrit after $72 \mathrm{~h}$ of life born by ECS, without influencing the $\mathrm{SpO}_{2}, \mathrm{HR}, \mathrm{T}$ and phototherapy. The placental transfusion by DCC gives to baby about $80-100 \mathrm{ml}$ of blood additional and $20-30 \mathrm{mg}$ of iron [15], this determines a great haemoglobin concentration in the newborns and best iron storage between 3 and 6 months of life and less incidence for transfusion and

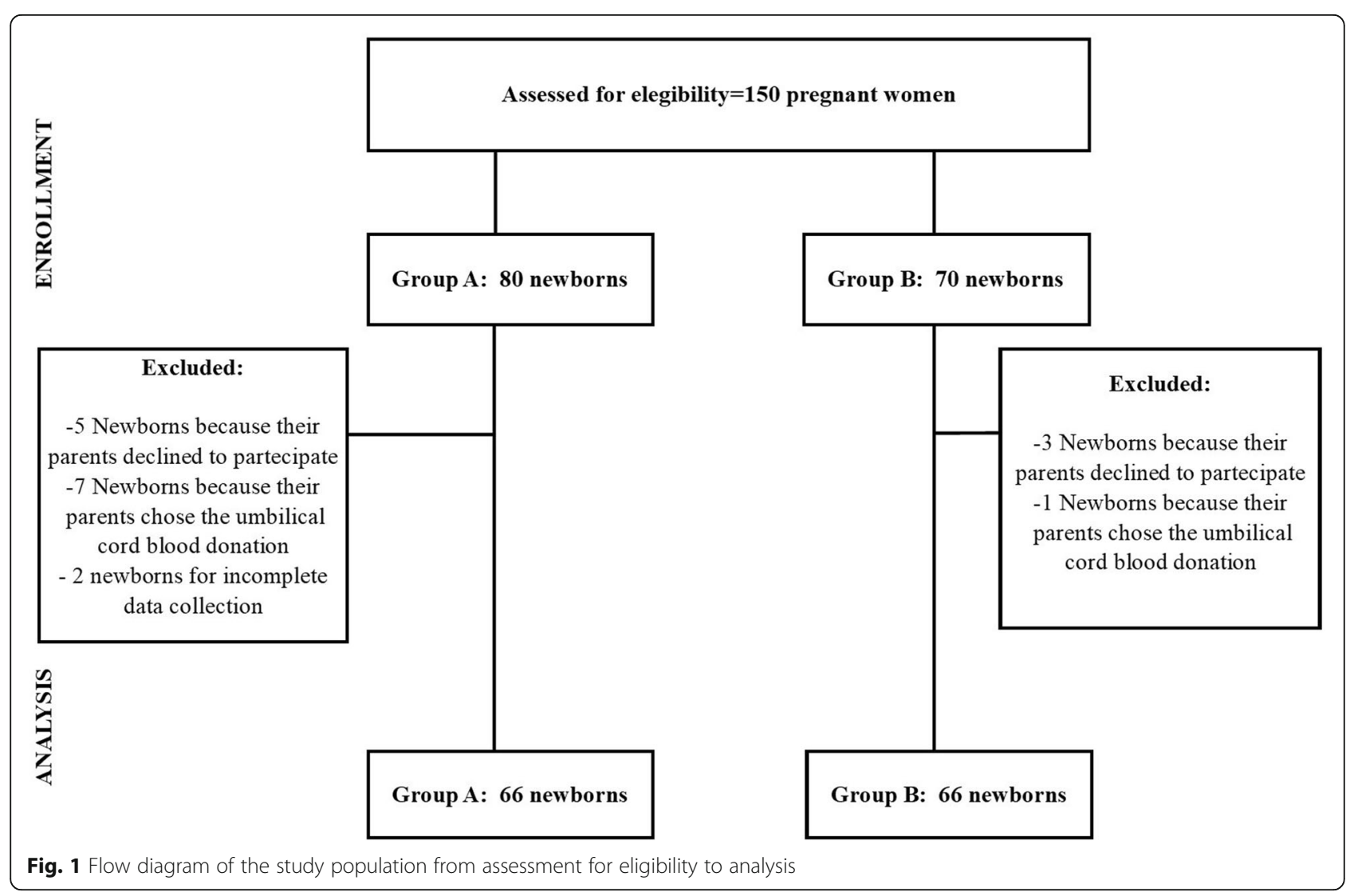


Table 1 Change in vital parameters, glycaemia, haematocrit and bilirubin in newborns subjected to DCC or ICC

\begin{tabular}{|c|c|c|c|c|c|c|c|c|}
\hline \multicolumn{2}{|c|}{ Outcome } & \multirow{2}{*}{$\begin{array}{l}\text { Time } \\
\mathbf{5} \mathbf{~ m i n}\end{array}$} & \multirow{2}{*}{$\frac{N}{132}$} & \multirow{2}{*}{$\begin{array}{l}\text { Group A } \\
88,98 \pm 7027\end{array}$} & \multirow{2}{*}{$\begin{array}{l}\text { Group B } \\
89,169 \pm 7453\end{array}$} & \multirow{2}{*}{$\frac{F(1,127)}{0,362}$} & \multirow{2}{*}{$\frac{\text { P_value }}{0,548}$} & \multirow{2}{*}{$\frac{\text { R-value }}{0,089}$} \\
\hline $\mathrm{SpO}_{2}$ & T0 vs T1 & & & & & & & \\
\hline & & $10 \mathrm{~min}$ & 132 & $95,328 \pm 3976$ & $96,046 \pm 3346$ & & & \\
\hline \multirow[t]{2}{*}{ HR } & T0 vs T1 & $5 \mathrm{~min}$ & 132 & $164 \pm 18,191$ & $157,89 \pm 15,66$ & 0,233 & 0,630 & 0,07 \\
\hline & & $10 \mathrm{~min}$ & 132 & $163 \pm 15,313$ & $155,86 \pm 13,571$ & & & \\
\hline \multicolumn{2}{|l|}{$\mathrm{T}\left({ }^{\circ} \mathrm{C}\right)$} & $5 \mathrm{~min}$ & 132 & $36,60 \pm 0,642$ & $36,64 \pm 0,640$ & - & 0,745 & - \\
\hline \multicolumn{2}{|c|}{ Glycaemia (mg/dl) } & $120 \mathrm{~min}$ & 132 & $60,32 \pm 9937$ & $56,02 \pm 17,101$ & - & 0,080 & - \\
\hline \multicolumn{2}{|c|}{ Ht (\%) } & $72 \mathrm{~h}$ & 132 & $51,56 \pm 6929$ & $56,71 \pm 6663$ & - & $0,001 *$ & - \\
\hline \multicolumn{2}{|c|}{ Bilirubin (mg/dl) } & $72 \mathrm{~h}$ & 132 & $7,06 \pm 2,76$ & $8,54 \pm 2,90$ & - & $0,004^{*}$ & - \\
\hline
\end{tabular}

neonatal hypotension $[6-9,16]$. Experimental studies, executed on animals and humans, analysed cardiocirculatory changes in the foetus immediately after birth and the importance of the DCC for the hemodynamic stabilization, particularly in the lowest gestational age Delayed cord clamping alters acid-base parameters and lactate values compared to immediate cord clamping $[2,3]$. . The timing of cord clamping was $180 \mathrm{~s}$ or longer demonstrating neurodevelopmental benefits in low-risk populations $[17,18]$. DCC after one minute is a practice that has been shown to be beneficial in spontaneous births [19-21]. The infants born by ECS showed a lower value of red blood cells than those birth by VD. The factors that affect placental transfusion appear to be uterine contractility. CS reduces placental transfusion due to maternal hypotension and insufficient uterine contractions [11-22]. Such reduction is even more pronounced by ECS than in emergency CS [11]. No differences in maternal bleeding complications were found with DCC in multiple pregnancies compared to ICC. DCC can be done safely in multiple pregnancies without any increased of maternal risk [23]. DCC is not possible without the parents' informed consent because this practice can alter the procedure to donation and collection of umbilical cord blood. Indeed, umbilical cord must be clamped and severed immediately to proceed with collection successfully. Our study evaluated whether the benefits that the DCC presented in the spontaneous births occur also for those born at term by ECS. Our data suggested that DCC was associated with an increase in haematocrit and bilirubin estimated at $72 \mathrm{~h}$ after birth. Although DCC was associated in a study [24] with an increase in phototherapy, in our study capillary bilirubin values were higher in the DCC group compared to the ICC group but without the need for phototherapy. Furthermore, no difference in statistical significance was found in $\mathrm{HR}$ and $\mathrm{SpO}_{2}$ between groups. These data were recorded in the first and 5th minute from birth. Wafaa at al. found greater values of $\mathrm{SpO}_{2}$ between newborns subjected to DCC compared to those treated by ICC, immediately after the birth.
However, at $6 \mathrm{~h}$ of life the difference was no longer found [4]. Yu L et al. did not consider the evaluation of $\mathrm{SpO}_{2}$ and $\mathrm{HR}$ in DCC group but considered as primary outcomes mortality, risk of iron-deficiency anaemia [20]. Similarly, Nevill at al. did not analyse oxygen saturation at birth but assessed the need for oxygen support which resulted lower in the group with DCC compared to ICC [9]. A large trial on 1510 newborns born by VD and randomized in DCC or ICC group reported higher values of $\mathrm{SpO} 2$ and lower value of $\mathrm{HR}$ at 1 and 5 min in DCC group with respect to IC [25]. These results encourage the use of DCC also in the newborns born by ECS as a valid tool to obtain a smoother cardiopulmonary transition. In our study although no statistical difference was found in HR and $\mathrm{SpO} 2$ although infants in the DCC group showed higher pre-ductal saturation values and lower HR values than those in the ICC group. This means that it is probably necessary to conduct a study in a larger sample size of newborns born by ECS to reveal a statistical difference between these variables. Finally, the temperature was evaluated for the potential heat loss during DCC. Data showed no clinically relevant temperature difference at the time of admission to the nursery between two arms, according to a recent systematic review [26]. The temperature variable was assessed in 11 trials involving 2317 preterm infants. Although there was moderate heterogeneity between studies a reduction of temperature in the group with DCC was not observed [26]. The strengths of our study included study design and attention for newborns born by ECS, however we investigated only the short-term outcome. It could be interesting to carry out studies about long-term outcomes such as iron concentration and neurodevelopment in childhood.

\section{Conclusion}

DCC in patients born by ECS is a valid practice and can be performed. DCC group improved HT blood values while did not influence $\mathrm{HR}, \mathrm{SpO}_{2}, \mathrm{~T}$ and glycaemia compared with ICC group. The lack of any difference in 
neonatal body temperature between the two modalities of clamping confirmed the safety of DCC also in this patient population. There was an increase in bilirubin in newborns born by DCC but without the need phototherapy. All together these results strongly support the hypothesis that DCC is better than ICC in term infants born by ECS.

\section{Abbreviations}

ICC: immediate umbilical cord clamping; DCC: delayed umbilical cord clamping; CS: caesarean section; VD: vaginal delivery; ECS: elective caesarean section; HR: heart rate; T: Temperature

\section{Acknowledgements}

The paper was represented as a poster in Conference: PAS Baltimore. EPAS2019: 3171118

\section{Authors' contributions}

Giuseppe De Bernardo designed the study. Maurizio Giordano performed statistical analysis. Rita De Santis revised the manuscript. Desiree Sordino, Serafina Perrone e Giuseppe Buonocore revised the manuscript and made substantial scientific contributions. The authors read and approved the final manuscript.

\section{Funding}

Not Applicable.

\section{Availability of data and materials}

The datasets generated and/or analysed during the current study are not publicly available due privacy reasons but are available from the corresponding author on reasonable request.

\section{Ethics approval and consent to participate}

The study was approved by Brescia Ethical Committee.

\section{Consent for publication}

Written informed consent was obtained from the families.

\section{Competing interests}

Not Applicable.

\section{Author details}

${ }^{1}$ Division of Pediatrics Neonatology and NICU, Ospedale Buon Consiglio Fatebenefratelli, Via Manzoni 220, 80123 Naples, Italy. ${ }^{2}$ Department of Clinical Medicine and Surgery, Federico II University, Naples, Italy. ${ }^{3}$ School of specialization in Pediatrics, Catholic University of the Sacred Heart Faculty of Medicine and Surgery, Rome, Italy. ${ }^{4}$ School of specialization in Pediatrics, University of Pavia Faculty of Medicine and Surgery, Pavia, Italy. ${ }^{5}$ Department of Emergency-NICU, A.O.R.N. Santobono-Pausilipon, Naples, Italy. ${ }^{6}$ Department of Woman's and Child's Health, University of Padova, Padova, Italy. ${ }^{7}$ Department of Molecular and Developmental Medicine, University of Siena, Siena, Italy. ${ }^{8}$ Department of Medicine and Surgery, University of Parma, Parma, Italy.

Received: 16 March 2020 Accepted: 17 May 2020

Published online: 24 May 2020

\section{References}

1. Katheria A, Hosono S, El-Naggar W. A new wrinkle: umbilical cord management (how, when, who). Semin Fetal Neonatal Med. 2018;23(5):3216. https://doi.org/10.1016/j.siny.2018.07.003 Epub 2018 Jul 20.

2. Bhatt S, Alison BJ, Wallace EM, Crossley KJ, Gill AW, Kluckow M, et al. Delaying cord clamping until ventilation onset improves cardiovascular function at birth in preterm lambs. J Physiol. 2013;591:2113-26 16.

3. Polglase GR, Dawson JA, Kluckow M, Gill AW, Davis PG, Te Pas AB, et al. Ventilation onset prior to umbilical cord clamping (physiologicalbased cord clamping) improves systemic and cerebral oxygenation in preterm lambs. PLoS One. 2015;10(2):e0117504. https://doi.org/10.1371/ journal.pone.0117504.
4. Wafaa T, Heba I, Hanan E. Effects of Deferred Versus Early Umbilical Cord Clamping on Maternal and Neonatal Outcomes. Am J Nurs Res. 2017;5(4): 115-28. https://doi.org/10.12691/ajnr-5-4-3.

5. Valero J, Desantes D, Perales-Puchalt A, Rubio J, Diago Almela VJ, Perales A. Effect of delayed umbilical cord clamping on blood gas analysis. Eur J Obstet Gynecol Reprod Biol. 2012;162(1):21-3. https://doi.org/10.1016/j. ejogrb.2012.01.020.

6. Alzaree F, Elbohoty A, Abdellatif M. Early versus delayed umbilical cord clamping on physiologic Anemia of the term newborn infant. Open Access Maced J Med Sci. 2018;6(8):1399-404. https://doi.org/10.3889/ oamjms.2018.286.

7. Ghavam S, Batra D, Mercer J, Kugelman A, Hosono S, Oh W, et al. Effects of placental transfusion in extremely low birthweight infants: meta-analysis of long- and short-term outcomes. Transfusion. 2014;54:1192-8.

8. Backes CH, Rivera BK, Haque U, Bridge JA, Smith CV, Hutchon DJ, et al, Placental transfusion strategies in very preterm neonates: a systematic review and meta-analysis. Obstet Gynecol. 2014;124:47-56.

9. Nevill E, Meyer MP. Effect of delayed cord clamping (DCC) on breathing and transition at birth in very preterm infants. Early Hum Dev. 2015;91:407-11 10. doi: 10.137.

10. Kc A, Rana N, Målqvist M, Jarawka Ranneberg L, Subedi K, Andersson O. Effects of delayed umbilical cord clamping vs early clamping on Anemia in infants at 8 and 12 months, A Randomized Clinical Trial. Jama Ped. 2017. https://doi.org/10.1001/jamapediatrics.2016.3971

11. Zhou YB, Li HT, Zhu LP, Liu JM. Impact of cesarean section on placental transfusion and iron-related hematological indices in term neonates: a systematic review and meta-analysis. Placenta. 2014;35:1-8.

12. Wyckoff MH, Aziz K, Escobedo MB, Kapadia VS, Kattwinkel J, Perlman JM, et al. Part 13: neonatal resuscitation: 2015 American Heart Association guidelines update for cardiopulmonary resuscitation and emergency cardiovascular care. Circulation. 2015;132(suppl 2):S543-60.

13. Faul $F$, Erdfelder $E$, Lang $A G$, Buchner $A . G^{*}$ power 3: a flexible statistical power analysis program for the social, behavioral, and biomedical sciences. Behav Res Methods. 2007;39(2):175-91. https://doi.org/10.3758/bf03193146.

14. Cohen J. Statistical power analysis for the behavioural sciences. New York: Academic Press; 1969

15. Duley LMM, Drife JO, Soe A, Weeks AD. In: Clamping of the Umbilical Cord and Placental Transfusion. In Scientific Impact Paper No. 14. Royal College of Obstetricians and Gynaecologists 2015. https://www.rcog.org.uk/ globalassets/documents/quidelines/scientific-impact-papers/sip-14.pdf. Accessed 1 May 2020

16. Andersson O, Hellström-Westas L, Andersson D, Domellöf M. Effect of delayed versus early umbilical cord clamping on neonatal outcomes and iron status at 4 months: a randomised controlled trial. Bmj. 2011;343:d7157. https://doi.org/10.1136/bmj.d7157.

17. Rao R, Bora R. Timing of umbilical cord clamping and infant brain development. J Pediatr. 2018;203:8-10. https://doi.org/10.1016/j.jpeds. 2018.07.080.

18. Andersson O, Lindquist B, Lindgren M, Stjernqvist K, Domellof M, HellstromWestas L. Effect of delayed cord clamping on neurodevelopment at 4 years of age: a randomized clinical trial. JAMA Pediatr. 2015;169:631-8. https://doi. org/10.1016/j.jpeds.2018.06.006

19. Mohammad K, Tailakh S, Fram K, Creedy D. Effects of early umbilical cord clamping versus delayed clamping on maternal and neonatal outcomes: a Jordanian study. J Matern Fetal Neonatal Med. 2019;15:1-7. https://doi.org/ 10.1080/14767058.2019.1602603.

20. Yu L, Sun Y, Shang Y, Yin M. Effect of timing of umbilical cord clamping on maternal and neonatal outcomes: a protocol for systematic review and network meta-analysis. Medicine (Baltimore). 2019;98(16):e15283. https://doi. org/10.1097/MD.0000000000015283.

21. Hutton EK, Hassan ES. Late vs early clamping of the umbilical cord in fullterm neonates: systematic review and meta-analysis of controlled trials. Jama. 2007;297(11):1241-52. https://doi.org/10.1001/jama.297.11.1241.

22. Ogata ES, Kitterman JA, Kleinberg F, Dong L, Willis M, Mates J, et al. The effect of time of cord clamping and maternal blood pressure on placental transfusion with cesarean section. Am J Obstet Gynecol. 1977;128:197-200. https://doi.org/10.1016/0002-9378(77)90687-1.

23. Ruangkit C, Leon M, Hassen K, Baker K, Poeltler D, Katheria A. Maternal bleeding complications following early versus delayed umbilical cord clamping in multiple pregnancies. BMC Pregnancy Childbirth. 2018;18(1): 131. https://doi.org/10.1186/s12884-018-1781-6. 
24. McDonald SJ, Middleton P, Dowswell T, Morris PS. Effect of timing of umbilical cord clamping of term infants on maternal and neonatal outcomes. Cochrane Database Syst Rev. 2013. https://doi.org/10.1002/ 14651858.CD004074.pub3.

25. Kc A, Singhal N, Gautam J, Rana N, Andersson O. Effect of early versus delayed cord clamping in neonate on heart rate, breathing and oxygen saturation during first 10 minutes of birth - randomized clinical trial. Matern Health Neonatol Perinatol. 2019;5:7. https://doi.org/10.1186/ s40748-019-0103-y.

26. Fogarty M, Osborn DA, Askie L, Seidler AL, Hunter K, Lui K, et al. Delayed vs early umbilical cord clamping for preterm infants: a systematic review and meta-analysis. Am J Obstet Gynecol. 2018;218:1-18.

\section{Publisher's Note}

Springer Nature remains neutral with regard to jurisdictional claims in published maps and institutional affiliations.

Ready to submit your research? Choose BMC and benefit from:

- fast, convenient online submission

- thorough peer review by experienced researchers in your field

- rapid publication on acceptance

- support for research data, including large and complex data types

- gold Open Access which fosters wider collaboration and increased citations

- maximum visibility for your research: over $100 \mathrm{M}$ website views per year

At $B M C$, research is always in progress.

Learn more biomedcentral.com/submissions 